\title{
Achieved Results, Problems and Future of Directive 2009/28/EC ("20/20/20 Directive")
}

\author{
Filip Rendulić ${ }^{1}$, Hrvoje Pirić ${ }^{1}$, Ivica Kuliš ${ }^{1}$, Marin Cerjan ${ }^{1}$
}

\begin{abstract}
Driven by increasing climate changes, the European Commission launched a plan to mitigate and combat them in early 2007. It took more than a year and a half for the plan to be passed after difficult negotiations among Member States. It was finally adopted by the European Parliament in late 2009. The Directive of the European Parliament and of the Council of Europe on promotion of renewable energy sources 2009/28/EC was adopted on 23rd April 2009 and it has become a part of the Energy and Climate Package of the European Union. It places great importance on renewable energy sources and confirms the 20-20-20 targets on increasing the share of energy production from renewable sources to 20 percent by 2020, increasing energy efficiency by 20 percent and reducing greenhouse gas emissions by 20 percent. In this paper, a review of previous achievements, problems and the future of the above plan is given.
\end{abstract}

\section{Keywords}

renewable sources, energy efficiency, greenhouse gas emissions, Directive 2009/28/EC

\section{Introduction}

Under its Directive 20/20/20, the European Union wants to make a contribution to environmental protection. The directive aims at increasing the share of renewable energy to $20 \%$, reducing energy consumption and $\mathrm{CO}_{2}$ emissions by $20 \%$, respectively. The deadline for achieving the objectives is 2020 , and the reference values for comparison are taken from 1990.

The supervision over the use of energy in Europe and the increased use of energy from renewable sources, energy savings and increased energy efficiency, with the United Nations Framework Convention on Climate Change and further obligations of the Community and international obligations associated with the reduction of greenhouse gas emissions after 2012, represent important parts of the package measures needed to reduce greenhouse gas emissions and meet the Kyoto Protocol. These factors have an important role in promoting the security of energy supply, encouraging technological development and innovations and providing opportunities for employment and regional development, especially in rural and remote areas. [1]

Technological improvements, incentives for the introduction of public transport and its expansion, the application of energy efficient technologies and the use of energy from renewable sources in transport are some of the most effective means by which the Community can reduce its dependence on imported oil in the transport sector in which the security of energy supply is the biggest problem.

In order to reduce greenhouse emissions and dependence on energy imports, the development of renewable energy sources and increased energy efficiency

This is an Open Access article distributed in accordance with the Creative Commons Attribution Non Commercial (CC-BY-NC-ND 4.0) license, which permits others to copy or share the article, provided original work is properly cited and that this is not done for commercial purposes. Users may not remix, transform, or build upon the material and may not distribute the modified material (http://creativecommons.org/licenses/by-nc/4.0/) 
should be closely related.

The final gross energy consumption from renewable sources in each Member State shall be calculated as the sum of: final gross electricity consumption from renewable energy sources, gross final consumption of energy from renewable sources for heating and cooling and final gross energy consumption from renewable sources in transport.

In order to achieve this primary objective, each Member State shall develop a national action plan for renewable energy which sets the overall national target for renewable energy sources according to the prescribed methodology and sectorial targets and trajectories in the production of electricity, energy for heating and cooling and transport energy from renewable energy sources.

Also, the National Action Plan is required to set the existing and planned policy for renewable energy sources as instruments, measures and mechanisms for achieving set goals until 2020.

\section{Plan realization to-date}

The primary production of energy from renewable sources has a long-term trend of growth. Between 1990 and 2013 , it has increased by $170 \%$ (the $4.4 \%$ average annual growth rate). However, in 2011, the primary production of renewable energy decreased by $0.4 \%$; mainly due to annual variations in hydropower generation. This is only the second drop since 1990 - first in 2002 (down 2.4\%), which is also a consequence of variations of hydropower production (due to unfavourable hydrological periods). [2]

After the period until 2010, during which a renewables share was growing strongly, the combined effect of warm weather, a slower progress of Member States in the implementation of the Renewable Energy Directive and the complicated economic situation in Europe led to a reduction in the use of renewable energy sources in 2011. However, the share of renewable sources in gross final energy consumption has increased because the consumption of fossil fuels was lower than the consumption from renewable energy sources. In 2012, the share of energy from renewable sources has increased again and reached $14.3 \%$, increasing further to $15 \%$ in 2013.

Hydropower plants create by far the largest share of electricity from renewable energy sources. The electricity production from hydropower plants has increased by $28 \%$ between 1990 and 2013, despite a reduction in their share in the total production of electricity from renewable sources from $94 \%$ to $43 \%$ over the same period. This was due to a faster expansion of electricity generation from other renewable sources. The electricity production from wind has more than tripled from 2005 to 2013 in comparison with 2000, which was the second largest contribution from renewable sources, replacing wood and other solid biomass, which held the second position from 1990. The increase in the electricity production from wind is conditioned by the construction of new wind power plants. Figure 1 gives an overview of the growth in the amount of installed wind power gigawatts over the years in the EU. [3]

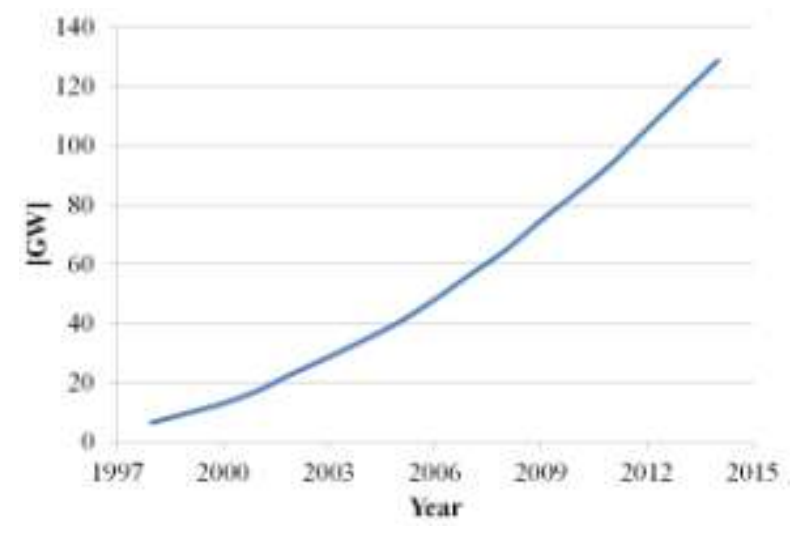

Fig. 1 Growth in installed capacity of wind power plants through the years

The electricity generation from solar energy has rapidly increased in recent years, and in 2013 amounted to $10 \%$ of overall renewable energy sources. Also, in 2013, electricity from solar energy has surpassed the one from wood and other solid biomass, which are now the third most important factor for the production of electricity from renewable sources. The increase in the amount of installed gigawatts of solar power plants in the EU is given in Figure 2.

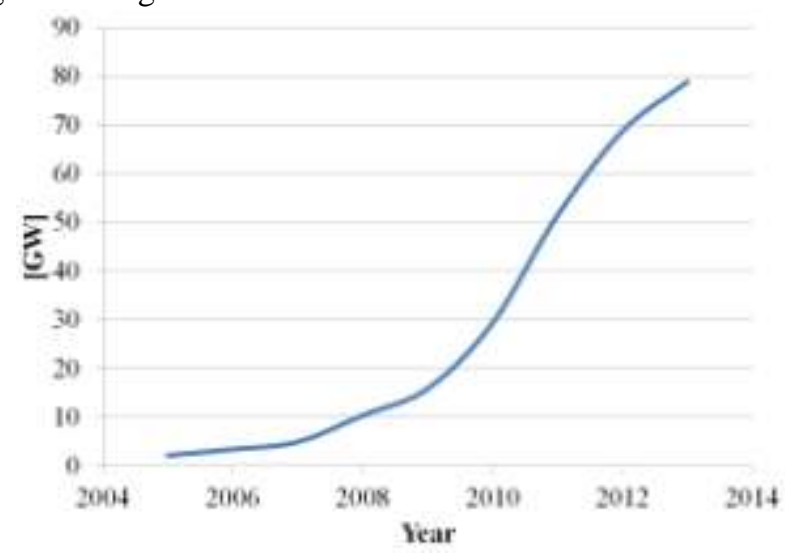

Fig. 2 Growth of installed capacity of solar power plants through the years

Solid renewable energy sources (wood and other solid biomass, except renewable waste) are also used in conventional thermal power plants. Their share in electric 
energy from renewable sources increased from $3.5 \%$ in 1990 to $9.5 \%$ in 2013. [3]

In 2013, the gross production of electrical energy from renewable energy sources has increased by $11 \%$ compared to 2012 .

The share of renewable energy sources in gross final energy consumption in the EU28 reached $15 \%$ in 2013, representing $75 \%$ of the target, which is $20 \%$ of electrical energy from renewable energy sources in the EU by 2020. (Fig. 3).

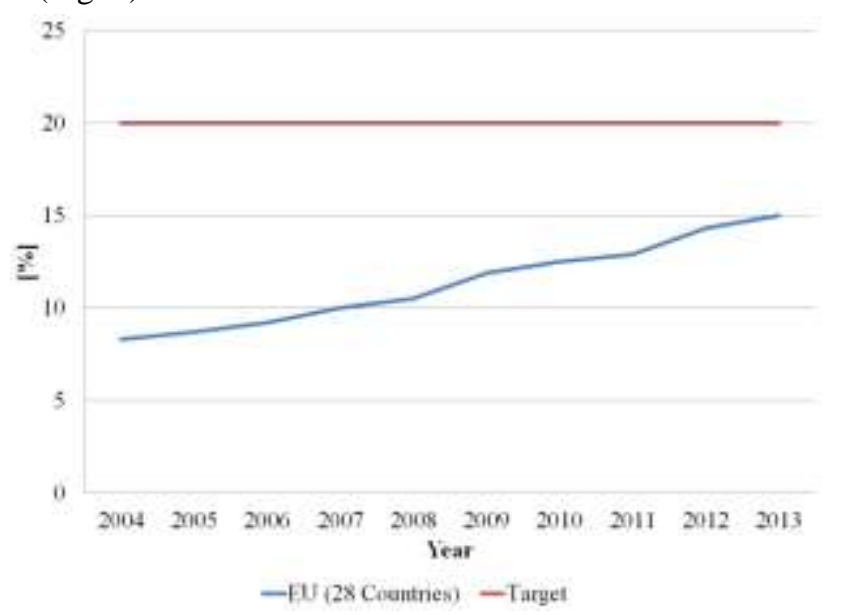

Fig. 3 Progress toward the goal of the $20 \%$ energy from RES in gross final energy consumption

The share of renewable energy sources represented $16.5 \%$ of the gross final energy consumption for heating and cooling, $25.4 \%$ of final electricity consumption and $5.4 \%$ of fuel consumption in transport in 2012.

The largest increase in the share of renewable energy sources in gross final energy consumption in the period 2005 to 2012 was registered in Sweden and Denmark (both $10.4 \%)$, Estonia (8.4\%), Austria (8.1\%) and Italy $(7.7 \%)$.

In 2013, the share of renewable energy in transport reached 5.4\% in the EU28. In 2005 it was 1.3\%, in 2010 $4.8 \%$ and in $20113.4 \%$. The share of renewable energy in gross final energy consumption by looking at countries in the European Economic Community, but not in the EU amounted to $76 \%$ in Iceland (associated with a high proportion of geothermal energy and hydropower) in 2012, 65\% in Norway (associated with a high share of hydropower), $12 \%$ in Turkey (2011) and 22\% in Switzerland (2010).

There are large differences between countries in
Europe because of the different starting points in the implementation of renewable energy sources in each country, differences in physical abilities to produce energy from renewable sources and differences in policies for encouraging renewable energy sources.

In 2013, renewable energy for heating and cooling amounted to $16.1 \%$ of the total final energy consumption for heating and cooling in the EU28, compared with $10.3 \%$ in 2005 and $14.2 \%$ in 2010 .

Renewable heat production from large CHP and thermal plants related to heat distribution network (derived heat) was 14\%. Renewable heating and cooling with heat pumps represents $8 \%$ of total energy from renewable sources for heating and cooling.

The major manufacturers of heat from biomass through cogeneration thermal plants are Sweden (26\%), Finland (15\%), Denmark (12\%), Germany (11\%) and Austria (8\%), which jointly amounted to $72 \%$ of the total use of biomass for heat production in cogeneration plants and thermal installations within the EU28 in 2012.

The share of renewable energy in the transport sector was $5.4 \%$ in the EU28 in 2013, compared with $1.3 \%$ in 2005

Since 2004, the share of renewable sources in gross final energy consumption has grown significantly in all countries with thirteen Member States that at least doubled their share of renewable energy in the last 10 years.

With $52.1 \%$ Sweden had in 2013 , by far the largest share of energy from renewable sources in gross final energy consumption, ahead of Latvia (37.1\%), Finland (36.8\%) and Austria (32.6\%). In contrast, the lowest shares of renewable energy sources were in Luxembourg (3.6\%), Malta (3.8\%), the Netherlands $(4.5 \%)$ and the UK $(5.1 \%)$. Three of the 28 EU Member States have already reached the level required to meet their national targets for 2020.: Bulgaria, Estonia and Sweden. Lithuania, Romania and Italy are less than 0.5 percentage points away from their 2020 goals. At the opposite end of the scale are the United Kingdom (9.9\% from the national target for 2020), the Netherlands (9.5\%), France $(8.8 \%)$ and Ireland $(8.2 \%)$ which are farthest from their goals.

A percentage share of energy from renewable sources in gross final energy consumption for each country of the EU is shown in Figure 4. 


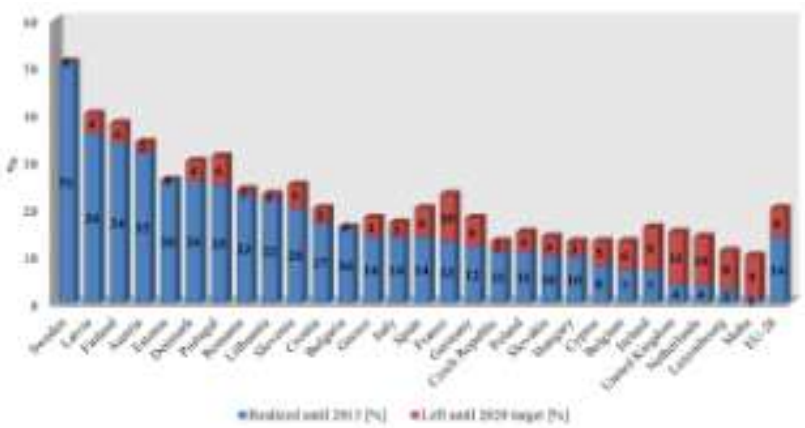

Fig. 4 The share of energy from RES in gross final energy consumption by country

Energy consumption in the European Union has fallen to a level last seen more than two decades ago. The drop in annual consumption in 2013, the year for which the latest research findings was more than $9 \%$ compared to its peak in 2006, and it is reflected in the continuing bad economic situation in Europe, as well as the efforts taken by the member States and companies to reduce energy consumption and improve energy efficiency. [4]

The energy consumption trends since 1990 is shown in Figure 5.

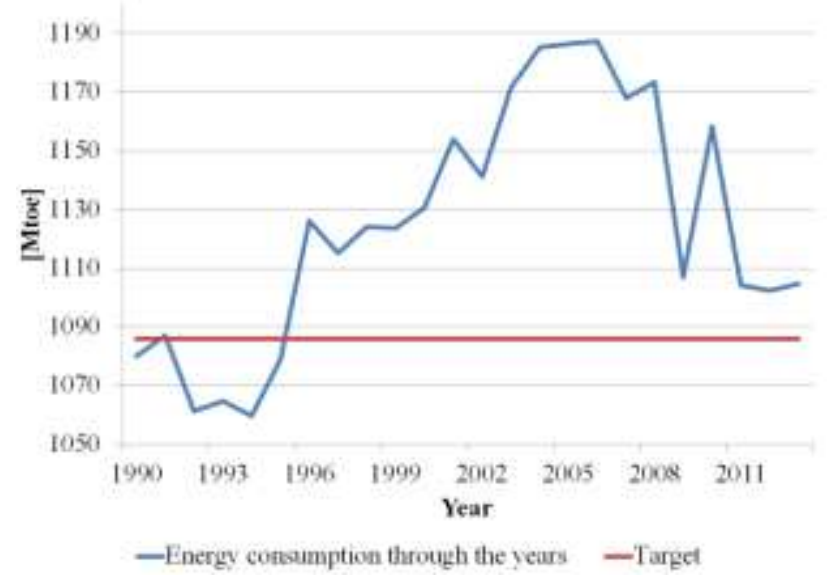

Fig. 5 Growth in installed capacity of wind power plants through the years

Reducing $\mathrm{CO} 2$ emissions by $20 \%$ by 2020 is also close to reaching its goal. The trend of reducing $\mathrm{CO} 2$ emissions is given in Figure 6. [5]

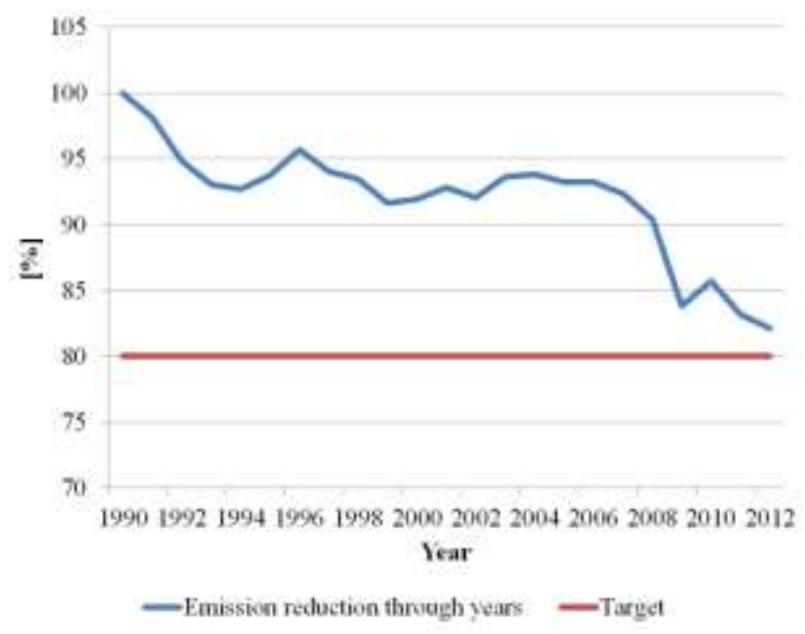

Fig. $6 \mathrm{CO} 2$ reduction through the years

\section{Problems and possibilities for advancement}

One of the biggest problems is disparity in tracking the 20-20-20 plan in EU countries. While some countries have already met most of the requirements, some are not even half way to achieving the given plan.

As previously mentioned, three of the 28 EU Member States have already reached the level required to meet their national targets for 2020: Bulgaria, Estonia and Sweden, while the United Kingdom (9.9\% from the national target for 2020), the Netherlands (9.5\%), France $(8.8 \%)$ and Ireland $(8.2 \%)$ are farthest from its goal.

In this article we will look at a problem that occurs during the overproduction of energy from renewable sources.

A great problem faced by all users of renewable energy sources is the unpredictability of the amount of energy that will be produced. The largest EU user of renewable energy is Germany. For the German system with its installed $40 \mathrm{GW}$ of wind power plants and about $35 \mathrm{GW}$ of solar power, even a very small change in weather conditions during the day can mean very large variations in the amount of electricity generated. One example is a surplus of renewable energy in Germany, especially from wind power plants in the fall and early winter, when their production is at their peak.

The electricity surplus is then delivered to the grid, which floods the neighbouring energy networks causing the overload of transmission systems, power outages or network losses when operators, due to significant changes in the system, are forced to shut the local power plants down. For example, the Czech transmission system 
operator CEPS supports the plan to build transformers in order to defend itself from the current supply produced by wind farms in Germany. The neighbouring country the Czech Republic has proposed not to install the protection if Germany agrees to pay penalties when it comes to the large influx of electricity from wind power. However, Germany refused.

Czech experts claim that Germany could solve this problem if it allows its operators to exclude local producers of electricity from renewable sources, when their production becomes too high. However, the proposed is not currently possible according to German law. Instead, Germany is planning to speed up the construction of a couple of thousand kilometres of the new transmission lines that would lead electricity from wind power plants in the north of the country to industrially strong south, which could help to solve the problem of overloading the neighbouring networks.

Another interesting thing happened after the declaration of a nuclear moratorium following the tragic events in Fukushima. Of course, the explanation for the moratorium is to increase safety. However, it can be very easy to conclude that an important role in this decision was played by lobbies that promote renewable energy sources.

So after the moratorium or the decision to conserve some of the existing nuclear power plants, Germany faced a couple of lawsuits.

Sweden energy group Vattenfall is seeking compensation for losses due to the decision of the German government to close older nuclear reactors. The claim is supported by the Swedish government. With Germany's E.ON and RWE, Vattenfall is most affected by the decision of Germany to gradually replace nuclear and fossil fuels with renewable energy sources. While RWE seeks 2 billion euro compensation for its reactors, E.ON seeks compensation in the amount of 8 billion euro.

After all, high prices at which the country buys electricity from renewable sources result in the increase of electricity price for industry and households.

Germany has decided to shut down its eight oldest nuclear reactors in March 2011 after the disaster in Japan. For the remaining nine nuclear power plants currently in operation, their closure is expected until 2022. It is estimated that the transition to green energy will cost German taxpayers up to 20 billion euro over the next decade.

Large electric power systems are not the only ones where the problems occur. Due to the high unpredictability of the amount of energy that will be produced from renewable energy sources, overproduction of renewable energy resources and giving priority to renewable energy sources during electricity production, causes a series of problems in every electricity system.

\section{Position of Croatia}

By joining the European Union on $1^{\text {st }}$ July 2013, the Republic of Croatia, together with other Member States, under the Directive 2009/28/EC on the promotion of the use of energy from renewable sources, committed to increase the use of energy from renewable sources. Until 2020, the share of energy from renewable sources in gross final energy consumption should be at least 20\%, observed at the level of the European Union. Croatia is very close to meeting the target of $20 \%$ of total energy consumption from renewable energy sources. As of 2013, $18 \%$ of overall energy consumption of Croatia is satisfied by renewables. Figure 7 shows the share and growth of RES in Croatia. [6], [7]

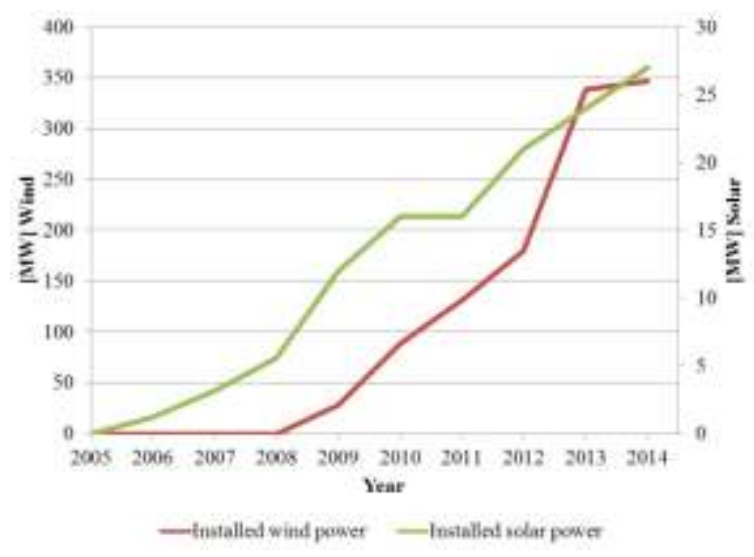

Fig. 7 Share and growth of RES in Croatia

\section{Conclusion}

Regardless of how hardly attainable the plan launched in 2007 by the European Commission to mitigate and combat climate change, it can be said that the European Union is very close to achieving it. The plan consists of three items, each of which is equally close to its realization. Plan for $20 \%$ of energy from RES in gross final energy consumption is currently at $15 \%$. Judging by the trend of increasing production and use of renewable energy sources, that plan should be met without difficulty. As for the plan to reduce energy consumption, it is necessary to reduce the consumption from 1104.6 Mtoe in 2013 to 1086 Mtoe in 2020. Thanks to increased incentives for energy efficiency and the current economic crisis in Europe, this plan should be easily achievable. The plan to reduce $\mathrm{CO} 2$ emissions by $20 \%$ in comparison 
to 1990 is perhaps the closest to its achievement and it is currently about 2 percentage points away from achieving the set for 2020 .

As previously mentioned repeatedly, one of the biggest problems is disparity in tracking the 20-20-20 plan in EU countries. While some states already meet most of the requirements, others are not halfway to achieving the set plan.

There is a number of other problems that the very implementation of the plan triggers and causes. The plan and its ideas themselves are very good and necessary, but it requires much improvement in its implementation.

\section{Reference list}

[1] A. Bonfiglio, F. Delfino, M. Invernizzi, F. Pampararo, G. Peveri, and R. Procopio, "Power system compensation and management strategies to meet EU 2020 climate\&energygoals," in 2012 IEEE Power and Energy Society General Meeting, 2012, pp. 1-8.

[2] J. Kajić, H. Pirić, F. Rendulić, M. Cerjan, and M. Delimar, "Impact of various hydro power generation scenarios on energy balance and power markets in SEE region," in DEMSEE 13, 2013, pp. 1-8.

[3] S. Cross, A. Hast, S. Syri, R. Kuhi-Thalfeldt, and J. Valtin, "Progress in development of renewable electricity in Northern Europe in the context of the EU 2020 renewables target," in 2013 10th International Conference on the European Energy Market (EEM), 2013, pp. 1-8.

[4] Database - Eurostat." [Online]. Available: http://ec.europa.eu/eurostat/data/database. Accessed: 07-May-2015].

[5] W. Tian and P. Da Costa, "Inequalities in per capita CO2 emissions in European Union, 1990-2020," in 11th International Conference on the European Energy Market (EEM14), 2014, pp. 1-5.

[6] "REN21 Renewable Energy Policy Network for the 21st Century." [Online]. Available: http://www.ren21.net/. [Accessed: 07-May-2015].

[7] I. Toljan, M. Tokai, and G. Skubin, "Development of construction of renewable energy sources in Croatia, Hungary and Slovenia through regional approach," in 2012 9th International Conference on the European Energy Market, 2012, pp. 1-7. 